\title{
Apoio institucional e cogestão: \\ a experiência da Política Nacional de Humanização \\ no Sistema Único de Saúde (SUS) no Distrito Federal, Brasil
}

Maria Elizabeth Mori(a)

Olga Vania Matoso de Oliveira(b)

Mori ME, Oliveira OVM. Institutional support and co-management: the experience of the National Humanization Policy in Brazilian Health System (SUS) at the Federal District, Brazil. Interface (Botucatu). 2014; 18 Supl 1:1063-75.

The institutional support in the Federal District (FD), Brazil, conducted by consultants from the National Humanization Policy of the Ministry of Health from 2008 to 2013 began at the Base Hospital (BHFD) and was extended to the Health Care Department. It aimed at changes in the models of care and management and, therefore, at strengthening of the SUS' network in the BHFD. At the BHFD, guidelines (as Co-management, Hospitality) and mechanisms (as Management Council, Management Board) were implemented. In the Health Care Department the support to dealing with overcrowding in the Urgency and Emergency sectors of the network's hospitals and to the establishment of co-management were implemented. We emphasize the importance of the managers' adhesion to guarantee the implementation of the National Humanization Policy and the achievement of the expected results.

Keywords: Brazilian Health System. National Humanization Policy. Institutional support. Co-management.
O apoio institucional no Distrito Federal (DF), Brasil, realizado por consultores da Política Nacional de Humanização (PNH), do Ministério da Saúde (MS), de 2008 a 2013, iniciou-se no Hospital de Base (HBDF), terciário, estendendo-se à Secretaria de Atenção à Saúde (SAS). A intervenção objetivou mudanças nos modelos de atenção e gestão e consequentemente, fortalecimento da Rede SUS no DF. No HBDF foram implementados diretrizes (Cogestão, Acolhimento, Ambiência) e dispositivos (visita aberta e direito ao acompanhante, Conselho Gestor, Colegiado Gestor, Acolhimento e Classificação de Risco, Programa de Formação em Saúde e Trabalho/PFST). Na SAS implementou-se o apoio ao enfrentamento de superlotação nas portas de Urgência e Emergência dos hospitais da rede e à constituição de Colegiado Gestor em redes de atenção prioritárias. Ressalta-se a importância da adesão dos dirigentes para a implementação da $\mathrm{PNH}$ e a realização dos resultados desejados.

Palavras-chave: Sistema Único de Saúde. Política Nacional de Humanização. Apoio Institucional. Cogestão.

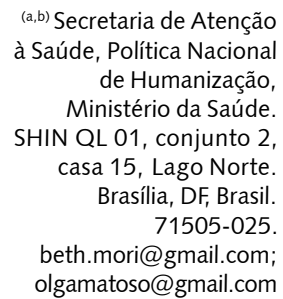

olgamatoso@gmail.com 


\section{Introdução}

O Sistema Único de Saúde (SUS), política pública inclusiva, é o resultado do movimento da reforma

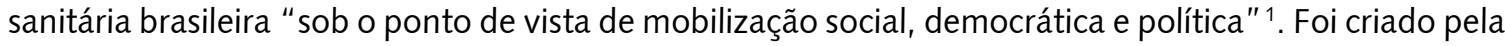
Constituição Federal de 1988 e regulamentado pela Lei Orgânica da Saúde (LOS), composta pelas Leis 8.080 e 8.142 de 1990. A Reforma Sanitária se deu no contexto de luta pelo poder entre segmentos da classe dominante e as divergências que se dão no interior da saúde pública, acirrando ainda mais o choque de interesses entre a medicina liberal e a saúde pública, problema que permanece até hoje na área da saúde pública nacional.

A $1^{\text {a }}$ Conferência Nacional de Saúde, ocorrida em 1941, ocupou-se de diferentes problemas relacionados aos mecanismos de gestão e de assistência, priorizando: a) organização sanitária estadual e municipal; b) ampliação e sistematização das campanhas nacionais; c) determinação das medidas para desenvolvimento dos serviços básicos de saneamento, e d) plano de desenvolvimento da obra nacional de proteção à maternidade, à infância e à adolescência ${ }^{2}$. Portanto, uma saúde que priorizou campanhas, a melhoria das condições sanitárias que interferem no adoecimento da população, além de privilegiar o cuidado da mulher-mãe, criança e adolescente.

Na décadas de 1960 e 1970, o modelo de atenção adotado era excludente para trabalhadores rurais, empregados domésticos e funcionários públicos, pois contemplava apenas trabalhadores que tinham carteira assinada. O governo militar, para atender o aumento dessa demanda, ao invés de investir em ampliação dos serviços públicos de saúde, opta pelo financiamento de reformas e ampliação da rede privada de hospitais por meio de empréstimos com juros subsidiados. Cria-se o Instituto Nacional de Assistência Médica da Previdência Social (INAMPS), que ajudou a intermediação do repasse de recursos públicos para a iniciativa privada, o que produziu um boom na rede privada e, em cinco anos, o número de leitos privados cresceu $500 \%$.

A $7^{a}$ Conferência Nacional de Saúde, última das realizadas durante o regime militar, já anunciava a necessidade de mudanças tanto no sistema de saúde quanto nas conferências de saúde, que só viriam a se concretizar após o início do processo de redemocratização do país. O sistema de saúde centralizado, fragmentado institucionalmente, com permanente descontinuidade administrativa, verticalizado e excludente, que se havia consolidado nas décadas anteriores, não respondia às necessidades expressas por amplos setores da sociedade, e o processo decisório fechado no espaço governamental era fortemente contestado pelo movimento social que se organizara em torno do setor.

É na década de 1980 que a saúde pública passa a ter uma fiscalização da sociedade. São criados: em 1981, o Conselho Consultivo de Administração da Saúde Previdenciária (CONASP); em 1982, o Conselho Nacional dos Secretários Estaduais de Saúde (CONASS) e, em 1988, o Conselho Nacional dos Secretários Municipais de Saúde (CONASEMS). Aumenta a participação da sociedade civil e, ao mesmo tempo, é criado o subsistema de Atenção Médico-Suplementar, inaugurando a era dos convênios médicos com expressiva adesão da classe média. A $8^{a}$ Conferência Nacional de Saúde (1986) é um marco na história da Saúde Pública Brasileira, ao aprovar as proposições do movimento sanitário brasileiro, que se organizava desde 1926, constituindo base para a garantia do temário - a saúde como direito e dever do estado - na Constituição Brasileira ${ }^{3}$.

O novo sistema de saúde - Sistema Único de Saúde (SUS) - além de preconizar a articulação das três instâncias de governo - federal, estadual e municipal -, inclui todos os cidadãos brasileiros e residentes no País, independentemente de serem ou não contribuintes da previdência social; promove a extinção do "indigente" assistido por "hospitais filantrópicos", e mantém os direitos da população de utilizar a rede privada e aderir aos planos de saúde.

Dez anos depois, o Ministério da Saúde (MS) publica a primeira portaria relacionada à humanização no atendimento, premiando hospitais infantis, embora não detalhasse as ações que caracterizariam um hospital humanizado. De lá pra cá, o MS continua preocupado com as questões de maus-tratos aos usuários e, em 2000, cria o Programa Nacional de Humanização da Assistência Hospitalar (PNHAH).

Dentre as várias políticas públicas de saúde, o MS lança, em 2003, a Política Nacional de Humanização (PNH), sem portaria, uma política transversal e inclusiva que objetiva fortalecer o SUS, ou seja, se dá na rede SUS por meio de adesão. A Política ${ }^{4}$ se estrutura nos princípios: 1 ) indissociabilidade 
entre o modelo de gestão e de atenção, 2) autonomia e protagonismo dos sujeitos (gestor, trabalhador e usuário), e 3) transversalidade. Oferta diretrizes voltadas para a implementação da cogestão, contrapondo-se ao modelo hegemônico vigente (gestão centralizada e estrutura organizacional verticalizada, burocrática e autoritária) e, para o modelo de atenção, propõe a clínica compartilhada oposta à assistência médico-centrada, hospitalocêntrica, medicalizante e com baixa participação da população. Disponibiliza, ainda, dispositivos e o método da tríplice inclusão (os sujeitos, seus coletivos e os conflitos decorrentes dessa aproximação), para promover mudanças nos processos de trabalho.

A PNH experimenta arranjos de cogestão em consonância com o SUS que propõe gestão participativa. No âmbito nacional da Política, são pactuadas as diretrizes norteadoras para a construção dos planos de ação pelos coletivos regionais 5 .

Em 2009, o coletivo regional centro-oeste prioriza o Distrito Federal (DF), explicitado no seu plano de ação, para apoio institucional intensivo, considerando os indicadores de morbimortalidade e as demandas de gestores e trabalhadores. Acrescenta-se que o DF tem especificidades em relação às demais unidades federadas do país, pois se compõe de duas esferas de governo, Federal e Distrital, com 28 Regiões Administrativas (RA's), nas quais estão incluídas as Regionais de Saúde. Portanto, a Secretaria de Saúde do DF (SES-DF) centraliza ações de gestão regional e de serviços, o que resulta na baixa autonomia dos gestores.

O processo de implementação da PNH na Rede de Saúde do DF se depara com desafios relacionados às dimensões política e técnica: a) sob o ponto de vista político, percebem-se dificuldades de conversas, ocasionando problemas de negociação e pactuação entre aqueles entes federados; b) sob o ponto de vista técnico, as dificuldades são ocasionadas pelo não-entendimento do que seja humanização em saúde, sendo associada à religiosidade, assistencialismo, paternalismo, caridade e solidariedade (o homem-figura-ideal, metro-padrão que não coincide com nenhuma existência concreta) ou, mesmo, ao tecnicismo de um gerenciamento sustentado na racionalidade administrativa e na qualidade total ${ }^{6}$. Há, também, falta de compreensão sobre o processo de trabalho que, segundo a $\mathrm{PNH}$, pressupõe o enfrentamento coletivo de problemas cotidianos das equipes multiprofissionais, exigindo atitudes técnico-clínico-políticas de corresponsabilização, para garantir, à população, o acesso com qualidade em todas as portas de entrada da rede SUS: atenção primária, especializada, urgência e emergência e hospitalar.

A rede hospitalar do DF está constituída por 16 hospitais gerais e o HBDF, inaugurado em 12 de setembro de 1960. Inserido numa rede hierarquizada de atenção à saúde pertencente à SES-DF, tem como missão o atendimento de alta complexidade, e foi certificado como Hospital de Ensino em dezembro de 2008, integrando ensino e pesquisa. O HBDF, com mais de três mil e quinhentos servidores, 748 leitos, sendo cem no Serviço de Emergência, é o hospital de

(c) Carlos Gama Pinto, Maria Elizabeth Mori, Olga V. Matoso de Oliveira e Simone Regine Eineck de Alcântara, consultores da $\mathrm{PNH}$, que contaram com a colaboração, no trabalho de apoio às equipes do HBDF, da médica cardiologista Maria Cristina Batista dos Santos. referência para atendimento terciário na rede. Atende toda a população do DF entorno e estados circunvizinhos.

O apoio institucional pelos consultores-apoiadores ${ }^{(c)}$ iniciou-se no HBDF pela sua importância na rede. No entanto, além de apoiar mudanças nos modelos de atenção e de gestão desse serviço, a intervenção estendeu-se à rede SUS/DF por meio das ações: implementação da gestão compartilhada (colegiados gestores), para inclusão dos trabalhadores na gestão do seu trabalho; resgate da participação do usuário nas decisões da gestão e do cuidado; priorização do atendimento segundo vulnerabilidade e risco para garantir o principio da equidade; e a 
desospitalização, pela gestão da clínica. Este artigo tem, portanto, como objetivo compartilhar a experiência do processo de apoio institucional.

\title{
Cogestão e apoio institucional
}

\author{
Em relação a cogestão, Campos $^{7}$ considera que
}

No Brasil, dentro do processo de implantação do Sistema Único de Saúde (SUS), há inúmeras experiências voltadas para ampliar a democracia em instituições de saúde. A descentralização de poder para os municípios (processo de municipalização) e a instalação de conselhos e conferências de saúde, com maioria de usuários, estão entre os principais dispositivos sugeridos pelo SUS para alterar o funcionamento burocrático do Estado. ( $p$. 864)

Entretanto, segundo o autor, tratam-se de medidas insuficientes para alcance dos objetivos do Sistema e redução do alto grau de alienação que se constata entre a maioria dos trabalhadores, uma vez que são pouco estimulados para ampliar sua capacidade de reflexão, de cogestão e, em decorrência, de realização profissional e pessoal.

A cogestão ou cogoverno, ou seja, todos decidindo, porém decidindo tendo em vista outras instâncias, deliberar entre interesses em pugna, em negociação permanente, em discussão e em recomposição com outros desejos, com outros interesses e com outras instâncias de poder. $^{7}$ (p. 867)

Nesse conceito, Campos ${ }^{7}$ propõe o Método de Gestão Colegiada que se baseia na participação de todos: ninguém decide só, isolado e em lugar dos outros. A gestão exercida pelo dirigente titular evolui para um colegiado formado de gestores e trabalhadores. Esse processo envolve conflitos relacionados aos interesses da Instituição, das categorias profissionais e dos usuários. O método não se propõe a resolver esses conflitos e eliminar contradições, por se tratar de um espaço que deve assegurar: possibilidades de participação, distribuição equilibrada do poder, objetividade, discussão, negociação, explicitação de diferenças, seguidas de sínteses operativas a serem colocadas em prática pelos trabalhadores, ou seja, "um processo de educação continuada em ato" 7 (p. 869).

Para a PNH, a gestão não é um lugar ou um espaço ou um campo de ação exclusiva de especialistas, portanto permite a inclusão dos vários sujeitos envolvidos no processo de trabalho, mais livres para a criação, autônomos e corresponsáveis pela coprodução de saúde. Além disso, a cogestão possibilita análise de contexto e problemas; processo de tomada de decisão, exercido por um conjunto mais ampliado de sujeitos que compõem a organização, assumindo-se o predicado de que "todos são gestores de seus processos de trabalho" ${ }^{8}$ (p. 24). Esta outra forma de gestão coletiva, derivada de pactos entre os sujeitos, e não de imposições sobre eles, traz para a produção de saúde a implicação e a corresponsabilidade pelo cuidado.

Para se efetivar a cogestão, Campos ${ }^{9}$ propõe o Método Paidéia ou da Roda, que objetiva "ampliar a capacidade de direção dos grupos aumentando sua capacidade de analisar e de operar sobre o mundo [práxis]. O método apoia, de modo simultâneo, a elaboração e implementação de projetos e a construção de sujeitos e de coletivos organizados" (p. 185).

O termo apoio é proposto pelo autor para se diferenciar da tradicional Supervisão do trabalho sustentada pelo poder e saber por parte de quem exerce diretamente o papel de supervisor. Apoio, portanto, tem como objeto de trabalho, coletivos que teriam o interesse e o desejo de transformar, de pensar e mudar suas práticas, de se produzir como sujeitos e de produzir novas realidades nas organizações de Saúde, comprometendo-se com outras instituições, de forma ética e corresponsável.

Além de traduzir uma relação mais circular e menos verticalizada nas instituições, o método oferta espaços coletivos de discussão quando analisa os processos de trabalho que incluem os desafios a serem enfrentados, define tarefas com prazos e responsabilidades. O método Paidéia pode ser autoaplicável 
pela direção e equipes ou incluir a figura do apoiador institucional, agente externo, que "facilita linhas de comunicação truncadas (o papel de mediador) e amplia o leque de ofertas que o grupo haveria de considerar e lidar"9 (p. 186).

Para tanto, o apoiador deve lidar com demandas de equipes, grupos e instituições, de forma a contemplar momentos, necessidades, interesses e desejos, mas, também, ofertar um modo corresponsável de produzir saúde, pela inclusão de diferentes sujeitos (gestor, trabalhador e usuário), dos movimentos (de outros coletivos da Instituição e fora dela) para o fomento de redes, e dos analisadores dos processos de trabalho (perturbações, tensões, conflitos e não-ditos que a inclusão produz) para a construção de novas possibilidades e sujeitos. Esse caminho é chamado pela PNH de Método da Tríplice Inclusão, um modo de operar em todo o território nacional, de forma intensiva (implementação da politica) ou extensiva (sensibilização e divulgação), tendo como um dos propósitos a desestabilização dos modos instituídos de se produzir saúde no SUS, para novos modos de produção, capazes de produzir também sujeitos e coletivos.

A Organização Mundial da Saúde (OMS) ressalta a formação de redes de atenção à saúde para superar a fragmentação das políticas e programas. A Atenção Primária à Saúde (APS) deve ser a ordenadora das redes para garantir a sustentabilidade dos sistemas públicos de saúde, sendo que cada nível de atenção deve operar de forma cooperativa e interdependente. Em 30 de dezembro de 2010, foi aprovada a Portaria n 4.279, que trata da organização da Rede de Atenção à Saúde (RAS), como “arranjos organizativos de ações e serviços de saúde, de diferentes densidades tecnológicas, que integradas por meio de sistemas de apoio técnico, logístico e de gestão, buscam garantir a integralidade do cuidado" 10.

Para tanto o MS elege o Apoio Integrado (AI) como estratégia para fortalecer a gestão do SUS com vistas à ampliação do acesso e da qualidade dos serviços de saúde. Trata-se de fomentar a relação com os outros entes federados (estados e municípios) para além das normas e da indução financeira, "aprendendo com os efeitos, aprimorando a prática gestora, a partir da análise de resultados em grupos plurais e implicados positivamente com mudanças para melhoria do SUS" ${ }^{10} \mathrm{com}$ a priorização de projetos de cooperação regional e a ação solidária entre os gestores.

Segundo essas diretrizes ${ }^{10}$, o apoiador deve estar sempre inserido em movimentos coletivos, buscando novos modos de operar e produzir nas organizações de acordo com os objetivos estratégicos da gestão federal e a metodologia do Al. É com base no princípio da PNH da indissociabilidade entre a atenção e gestão que a função de apoio institucional opera: 1) fomentando espaços coletivos, por meio de arranjos ou dispositivos que fortaleçam a integração entre sujeitos; 2 ) admitindo as relações de poder, afeto e circulação de saberes; 3 ) incentivando a construção coletiva com pactuação de compromissos e contratos; 4) despertando o olhar avaliativo no decorrer dos processos; 5) estimulando a capacidade crítica dos sujeitos, gerando processos transformadores das práticas de saúde, para melhorar a qualidade da atenção e da gestão no SUS.

Concluindo, o apoiador desempenha as tarefas de:

Ativar coletivos, conectar redes e incluir a multiplicidade de olhares e práticas, interesses e desejos para produção de objetivos comuns, na implementação das Políticas de Saúde. Portanto, são necessários mecanismos de cogestão, para que gestores e trabalhadores possam olhar para o próprio trabalho, para suas relações no serviço, para as relações das equipes com os usuários, para que mudanças possam ocorrer. ${ }^{10}$ (p. 9)

\section{Apresentação da experiência}

A implementação da PNH no DF exigiu, diante do cenário encontrado, uma aposta de gestores e trabalhadores na mudança dos modos tradicionais de gestão e atenção adotados. $\mathrm{E}$, ainda, problematizou a relação dos entes federados, usualmente vinculada ao repasse de recursos financeiros, mas sem intervenção nos modos de cuidar e de gerir a Saúde. O método da $\mathrm{PNH}$, que não envolve financiamento, propõe outro modo de fazer atenção e gestão, colocando, em análise, o modelo 
vigente, com suas práticas frequentemente desumanizantes e contraditórias ao movimento sanitário. Tensionando, perturbando o instituído, mas, sobretudo, fazendo junto.

No apoio ao HBDF, partimos de duas situações: demanda de profissional da medicina que apresentava adoecimento decorrente do processo de trabalho no Pronto do Socorro (PS), e prática insipiente de gestão colegiada já existente na diretoria do Hospital, modo contra-hegemônico de gerir a saúde no fazer cotidiano e em consonância com a PNH.

Iniciado o apoio institucional ao HBDF, foi realizado contato com a direção geral para discutir a implementação da $\mathrm{PNH}$, com as seguintes estratégias de oferta: 1) visita técnica ao Hospital Municipal Odilon Behrens (HMOB) em Belo Horizonte/MG, uma experiência bem-sucedida do SUS, resultante do apoio técnico, político e financeiro do Ministério, via PNH. O hospital tem sido referência nacional da Política e centro de formação de apoiadores institucionais (gestores, trabalhadores e usuários de outros municípios e estados); 2) apoio semanal da PNH e da Unicamp ao Colegiado Gestor da Direção; 3) realização do Curso de Extensão em Gestão de Sistemas e Serviços de Saúde para gestores e trabalhadores do referido hospital, parceria do MS/PNH com o Departamento da Medicina Preventiva da Unicamp (SP), segundo o princípio pedagógico de que formar é intervir; 4) pactuação do apoio institucional intensivo, semanal, aos participantes do curso (Equipes do PS, Unidades da Internação e Ambulatório), que elaborariam Planos de Intervenção (PI), considerando o dia a dia do trabalho e os conhecimentos desenvolvidos durante o processo de formação.

Após visita técnica ao HMOB, a Direção do HBDF, em decisão colegiada, escolheu a PNH como norteadora de sua gestão. A despeito dos desafios no cenário técnico-político-administrativo, a PNH revelou sua potência no decorrer do processo, conforme as realizações abaixo:

\section{a. Diretriz visita aberta e direito a acompanhante}

A primeira demanda da gestão pactuada para apoio da PNH foi a ampliação do horário de visita aos pacientes internados no PS e nas Unidades de Internação, como forma de garantir o contato do paciente com sua rede sociofamiliar e os demais serviços da rede de saúde, preservando o projeto de vida do paciente.
A pessoa internada é isolada do convívio cotidiano e sua rede social (familiares, amigos e comunidade) e destituída de qualquer papel no processo de cuidado. Observamos tal visão materializada tanto na planta física dos hospitais, onde não há espaço para acompanhantes nem para visitantes, quanto nas rotinas hospitalares, que também não consideram a importância dos familiares e dos parceiros (ou seja, da rede social) para o cuidado. Assim, ocorre que a pessoa doente, quando internada em uma unidade de tratamento, perde parte ou toda a sua autonomia. Dessa forma, o que chega até ela, vindo dos seus entes queridos, tem a potência de induzi-la à retomada de si e, em decorrência, contribuir para a sua reabilitação. ${ }^{11}$ (p. 5)

Para tanto, foram realizadas oficinas e reuniões sobre o tema da humanização: 1) com os trabalhadores e gestores, tendo como resultado a ampliação do horário de visitas de trinta minutos/dia para seis horas/dia. Essa ação foi amplamente divulgada tanto para dentro do Hospital quanto externamente, por meio da mídia local; 2) com os acompanhantes (representantes da rede social da pessoa internada que a acompanha durante sua permanência nos ambientes de assistência à saúde), reuniões diárias (manhã e tarde) com o objetivo de incluí-los na prática do cuidado, reduzir reinternações, ampliar a conversa entre profissionais e usuários, problematizar o funcionamento do hospital, discutir os direitos e deveres dos usuários. Além dos acompanhantes, também participavam os representantes das áreas técnicas (nutrição, enfermagem, medicina, psicologia, serviço social). 


\section{b. Diretriz acolhimento}

No processo de ampliação do horário da visita, o trabalho dos apoiadores se viu convocado para problematizar o conceito de acolhimento, considerando o modo como os usuários eram atendidos no Hospital. Para a PNH, o acolhimento expressa uma ação de aproximação, um "estar com" e "perto de", ou seja, uma atitude de inclusão, de estar em relação com algo ou alguém.

O acolhimento não é um espaço ou um local, mas uma postura ética; não pressupõe hora ou profissional específico para fazê-lo, mas implica necessariamente o compartilhamento de saberes, angústias e invenções; quem acolhe toma para si a responsabilidade de "abrigar e agasalhar" outrem em suas demandas, com a resolutividade necessária para o caso em questão. Desse modo é que o diferenciamos de triagem, pois se constitui numa ação de inclusão que não se esgota na etapa da recepção, mas que deve ocorrer em todos os locais e momentos do serviço de saúde. ${ }^{12}$ (p. 17)

O acolhimento no campo da saúde deve ser entendido como ferramenta tecnológica relacional de intervenção na escuta, na construção de vínculo, na garantia do acesso com responsabilização e na resolutividade dos serviços.

Foram realizadas oficinas semanais com trabalhadores da porta de entrada do PS (maqueiros, da enfermagem, da segurança, administrativos e acadêmicos do Programa Posso Ajudar (SES/DF), envolvendo ações de recepção, preenchimento da Guia de Atendimento de Emergência (GAE), orientação de fluxo interno, sinalização, informação quanto aos serviços da rede interna e externa, conforme a demanda dos usuários. Nas discussões, percebeu-se que o atendimento era por ordem de chegada e grande parte dos pacientes vinham do Ambulatório do HBDF, devido a cancelamentos de consultas eletivas. Isso contribuía para o aumento da superlotação da Emergência.

A partir dessa análise, junto à equipe, ofertamos a implementação do Dispositivo Acolhimento e Classificação de Risco (ACR) no PS, para ordenamento do acesso segundo vulnerabilidade e risco, adotando-se o protocolo de Campinas/SP. E, para discussão e validação desse protocolo, foram realizadas oficinas com os médicos e com a enfermagem sobre o BLS (Basic Life Support), com apoio institucional matricial da PNH em todo o processo. A divulgação desse novo modo de funcionamento do PS se deu pela mídia local, além de faixas nas imediações do Hospital, banners internos e distribuição de folhetos sobre ACR para usuários, trabalhadores e gestores.

\section{c. Diretriz ambiência}

Nesse processo de apoio institucional, a ambiência também constitui um tema de intervenção, uma vez que observamos a incompatibilidade entre o espaço físico, o número de pacientes internados e circulação de trabalhadores, acompanhantes e visitantes. Ressaltou-se, também, o desvio do papel do PS, que tem funcionado como unidade de internação. Como consequências desumanizantes, observava-se a não-garantia da privacidade, pacientes em macas e cadeiras por conta da superlotação, dentre outras.

Para a PNH, Ambiência hospitalar refere-se a:

\begin{abstract}
Tratamento dado ao espaço físico entendido como espaço social, profissional e de relações interpessoais que deve proporcionar atenção acolhedora, humana e resolutiva. Ou seja, espaço que possibilita reflexão da produção do sujeito e do processo de trabalho; que visa a confortabilidade focada na privacidade e individualidade dos sujeitos envolvidos, exaltando elementos do ambiente que interagem com o homem - a dizer, cor, cheiro, som, iluminação, morfologia... -, e garantindo conforto a trabalhadores, paciente e sua rede social; como ferramenta facilitadora do processo de trabalho funcional favorecendo a otimização de recursos e o atendimento humanizado, acolhedor e resolutivo. ${ }^{13}$ (p. 5)
\end{abstract}

Foram realizadas palestras e oficinas sobre ambiência, para gestores e trabalhadores, sobre o espaço físico como produtor de encontros entre sujeitos, o que originou a elaboração de projeto arquitetônico para reforma da ambiência do PS, com consultoria matricial da $\mathrm{PNH}$ e a equipe multiprofissional da Emergência. 


\section{d. Diretriz cogestão}

Nos serviços públicos de saúde, ainda são poucos os espaços em que as experiências são discutidas e compartilhadas. A luta por melhores condições de trabalho é um exercício ético, que aponta para uma avaliação permanente das práticas e seus efeitos sobre a vida de todos e de cada um.

O apoio à implementação da cogestão se iniciou com o Colegiado Gestor (CG) de diretores representantes das áreas administrativo-financeiro, clínica, ambulatorial, laboratorial, PS etc. - já existente. Posteriormente, constituíram-se outros CG em diversas unidades de produção hospital: Cardiologia, Radiologia, Central de Material Esterilização (CME), Centro Cirúrgico (CC), PS, Ambulatório, Pediatria, Unidade de Terapia Intensiva (UTI) pediátrica, implicando gestores e trabalhadores nas análises sobre o processo de trabalho e tomada de decisões. Além disso, apoiamos a recomposição do Conselho Gestor do hospital, promovendo o protagonismo de usuários nos processos de gestão e atenção do HBDF e na presidência desse conselho, e, também, a elaboração de projeto de nova estrutura organizacional do HBDF em unidades de produção e apoio matricial. Esse projeto não foi implementado devido à mudança da gestão promovida pelo novo governo do DF, em 2011 .

\section{e. Diretriz saúde e trabalho}

A proposta da PNH nessa diretriz é a de ampliar a compreensão sobre inseparabilidade entre o processo de produção de saúde/adoecimento dos trabalhadores e os processos de trabalho que estão inseridos.

O trabalho é composto por contradições, apresentando-se ao mesmo tempo como espaço de criação e de repetição; espaço de exercício da vontade, ação pelo constrangimento de outrem; trabalho para si e trabalho demandado do/pelo outro, encarnado em sujeitos e coletivos que portam necessidades (sempre sócio-históricas). ${ }^{8}$ (p. 14)

Portanto, não é apenas o que está prescrito para ser executado, mas tudo se realiza incluindo a criação do trabalhador, o esforço dispendido no cotidiano profissional, os acordos e pactos realizados, mesmo aquilo o que se pensou em fazer, mas não se realizou. ${ }^{14}$ (p. 9)

Neste sentido, foi constituída a Comunidade Ampliada de Pesquisa (CAP), no PS, com base no dispositivo Programa de Formação em Saúde e Trabalho (PFST), para identificação das causas do adoecimento no trabalho, e apoiada a intervenção, pelos trabalhadores, na melhoria do processo de trabalho com vistas à saúde do trabalhador.

\section{f. Diretriz formação e intervenção}

A PNH afirma quatro princípios: 1) Inseparabilidade entre formação e intervenção, com as máximas "transformar para conhecer a realidade" e "aprender fazendo". Problematiza a experiência concreta do trabalho em saúde, ao demonstrar, pelo apoio institucional, que formar não se restringe a cursos; 2 ) Toda formação implica análise do processo de trabalho em saúde; 3) Articulação e integração da rede de saúde, com projeto de formação articulado à realidade e necessidade local, para aumentar o grau de conversa e pactuação entre os diversos pontos da rede; 4) Planejamento e avaliação são indissociáveis da formação, reafirmando o olhar avaliativo durante todo o processo.

Durante os anos de 2010 e 2011, realizamos a capacitação de 54 trabalhadores e gestores do HBDF e para mais 62 profissionais das demais regionais de saúde do DF, por meio do curso de extensão. Este movimento de capacitação foi priorizado para Atenção Hospitalar devido à expressiva demanda do usuário nesse serviço, sobretudo por falta de acesso na Atenção Básica (AB), ainda que ordenadora do Sistema. Consequentemente, durante o trabalho de apoio institucional, problematizamos a necessidade de constituição do trabalho em rede de atenção à saúde no DF. Durante o curso, o apoio se estendeu às 
demais equipes dos hospitais para elaboração de PI's, com mudanças nos processos de trabalho do PS, Ambulatório e Unidades de Internação.

Nessa época, apoiamos a discussão, das equipes da Pediatria Terciária do HBDF e do Hospital de Apoio, sobre a necessidade de trabalho comum, fomentando grupalidade na linha de cuidado à criança, que, posteriormente, seriam incorporadas no novo Hospital da Criança de Brasília José Alencar. Destacamos avanços, também, na implementação da Cogestão no Hospital de Apoio de Brasília (HAB) e no Hospital Regional do Gama (HRG), com a constituição de colegiados gestores. Neste último, apoiamos: a qualificação do ACR com problematização da Ambiência no Pronto Socorro Adulto (PSA), ampliação do horário de visita, além da Atenção Primária, com colegiados gestores e projeto de expansão da Estratégia Saúde da Família (ESF).

O apoio institucional permitiu um aprendizado, tanto para os apoiadores quanto para gestores e trabalhadores, de que não há necessidade de se constituir um Grupo de Trabalho de Humanização (GTH) como "o responsável" pela implementação da humanização. Se houver decisão política da gestão, implicação conjunta das equipes e inclusão de usuários como parceiros no enfrentamento dos desafios, com certeza haverá mudanças nos processos de trabalho de cuidar e gerir. Esta afirmação se baseia na estratégia utilizada: durante o processo de apoio foram criadas frentes de trabalho temáticas, de caráter provisório, conforme cada diretriz e/ou dispositivo da $\mathrm{PNH}$ implementado.

No início de 2011, com o novo governo, o apoio foi comprometido devido à troca de diretores e equipes que haviam promovido as inovações citadas acima. Em fevereiro deste ano, realizamos reuniões com o diretor de Projetos Estratégicos da Secretaria de Estado da Saúde do DF, ligado ao gabinete do secretário de Saúde, para retomada da parceria entre PNH/MS e SES/DF. Esse Escritório assume a PNH como política estruturante no enfrentamento da superlotação nos PS's da Rede. Em junho, como decorrência do apoio intensivo àquela diretoria, foi criada nova coordenação geral PNH-SES/DF, com recomposição da equipe - apoiadores institucionais formados no curso de Gestão - para constituição do grupo condutor da Política, que passa a atuar em cogestão. Este Colegiado de coordenadores regionais PNH SES/DF, com as 16 regionais de Saúde, reúne-se semanalmente até o presente momento, com apoio intensivo dos consultores.

Com apoio da PNH, o Escritório e a Coordenação apresentam, ao Colegiado de subsecretários e diretores regionais da SES/DF, proposta de enfrentamento da superlotação dos PS's, segundo quatro eixos prioritários: 1) Implementação do ACR em todas as portas de Urgência e Emergência; 2) Gestão de leitos - constituição de CG de leitos, com a inclusão do Núcleo Regional de Atenção Domiciliar (NRAD); implantação da ferramenta Kambam, no setor de emergência e nas unidades de internação; criação do quadro de acompanhamento dos indicadores do processo e de resultados da gestão de leitos, na sala de situação do setor de gestão de emergência; 3) Reorganização da equipe assistencial do setor de emergência, com a horizontalização da equipe médica e de enfermagem; 4) Gestão da rede - criação do CG da rede regional, com inclusão do NRAD; apresentação da capacidade instalada da Atenção Primária de Saúde (APS) regional (quantidade de Centros de Saúde e Unidades Saúde da Família, com adscrição da área de abrangência, serviços ofertados e mapeamento de $\mathrm{RH}$ ); apresentação da capacidade instalada da Atenção Secundária/Especializada da regional (serviços ofertados e mapeamento de RH); apresentação da referência terciária regional (especialidades, serviços e locais a serem referenciados); adequação/ constituição dos fluxos de referência e contrarreferência da rede, conforme protocolos estabelecidos pela SES; otimização das ações do Comitê Central de Urgência e Emergência.

Em 2012, o diretor desse Escritório assume a Secretaria de Atenção à Saúde (SAS) do DF. Mantém as ações acima com ampliação dos pontos de atenção da rede de urgência. Cria o CG de Emergências da SES - Diretores de Atenção à Saúde (DAS), gerentes de Emergências e gerentes de gestão de leitos dos hospitais regionais - para efetivar a rede de Urgência e Emergência (RUE). Em outubro, são incluídos, nesse CG, os coordenadores regionais e consultores da PNH. Como resultado desse processo, foi criado, em todas as regionais, o Ambulatório de Referência, para pacientes classificados em verdes e azuis, que diminuiu significativamente a demanda nas portas dos hospitais, garantindo o atendimento na Atenção Primária (AP) por meio de encaminhamento responsável. 
No nosso Plano de Ação no DF, priorizamos o apoio à Coordenação da PNH na SES/DF e ao Colegiado Regional de Coordenadores Regionais da $\mathrm{PNH}_{\text {, por }}$ necessidade de avançarem: no modo de funcionamento, na apropriação dos conceitos e no método da Tríplice Inclusão da Política, no exercício da função apoio e maior autonomia e protagonismo nos Colegiados Gestores (CG's) Regionais constituídos.

Ressalta-se que, neste ano, ao reconhecer o apoio institucional - ferramenta da $\mathrm{PNH}$ para mudar a relação entre os entes federados -, o MS cria o Apoio Integrado (Al), a ser operado em cada estado por equipes de referência (apoiadores generalistas e temáticos) cujas ações priorizam os projetos de cooperação às regiões de saúde e especificidades estaduais, conforme o Decreto $\mathrm{n}^{\circ}$ 7.508. Assim, retomamos o apoio institucional integrado no HBDF no Programa SOS Emergência ${ }^{(\mathrm{d})}$ pelo $\mathrm{NAQH}^{(\mathrm{e})}$. É pactuada a gestão da clínica como outra estratégia para desospitalização, reduzindo o número de pacientes internados no PS da Ortopedia.

Em 2013, a gestão colegiada na SAS/DF se amplia, por decisão politica do Secretário e nosso apoio. Além do CG Emergências da SES, cria-se o CG da Rede Cegonha $(R C)^{(f)}$. Este constitui-se pelo grupo condutor da RC da SES/DF, DAS's, coordenadores da neonatologia e gineco-obstetrícia, gerentes da gestão de leitos no PS e coordenadores regionais da PNH. O secretário reúne-se semanalmente, de forma alternada, com esses CG's, o que representa um movimento contrahegemônico à "politica de gabinete" - "manda quem pode obedece quem tem juízo" - para a construção coletiva de ações para enfrentamento das dificuldades trazidas, em forma de "casos" do dia a dia em seus territórios, pelos Colegiados.

\section{Análise e considerações finais}

Os resultados do apoio institucional do coletivo de consultores para o DF demonstram avanços na mobilização de equipes para as mudanças na atenção e gestão. Entretanto, a desproporção entre a demanda de implementação da PNH na rede e o número de consultores dificultou o apoio intensivo aos processos de intervenção disparados pelo Curso. Os consultores assumiram o desafio dessa demanda pelo fato de, pela primeira vez, o DF querer firmar parceria com a PNH e por contarem com a monitoria de acadêmicas ${ }^{(g)}$ de Psicologia. Ressaltamos, ainda, que o apoio intensivo semanal às equipes dos demais hospitais e, também, ao HBDF nem sempre aconteceu como planejado, uma vez que outros processos de formação da PNH ocorreram simultaneamente, dificultando a participação de outros consultores da Política, nesse tipo de apoio.

A falta do apoio intensivo semanal aos serviços contribui para retorno do cenário anterior: trabalho regido por rotina prescrita e focado em corporações profissionais. A falta da análise dos processos de trabalho impede a produção de saúde e de sujeitos. Em geral, não há enfrentamento coletivo dos problemas pelos trabalhadores adoecidos, que permanecem na queixa, sem potência para intervir nas práticas desumanizantes. Ideias inovadoras são vistas como ações "piratas", desvinculadas e até contrárias às normas, como se estas dessem conta do trabalho. A responsabilidade de solução costuma ser transferida para outras instâncias, ainda que muitas soluções sejam de governabilidade das equipes. Geralmente, os processos de trabalho que produzem sofrimento ao trabalhador e não garantem os direitos dos usuários deixam de ser tratados como analisadores. Esse "não dito" contribui para a falta de sentido no trabalho. O olhar externo do apoiador fomenta (d) Criado pelo governo federal para humanizar e qualificar o atendimento nas redes de Urgência e Emergência, reduzir filas e tempo de espera por atendimento. Prioriza o apoio a 12 hospitais brasileiros (dentre eles o HBDF) no investimento financeiro de 3,6 milhões ano para a assistência, e três milhões para reformas físicas e/ou compra de equipamento, além do pagamento diferenciado dos leitos de retaguarda.

(e) Núcleo de Acesso e Qualidade Hospitalar, composto por representantes do MS, da SES/DF e do HBDF

(f) Estratégia do MS, operacionalizada no SUS, fundamentada nos princípios da humanização e assistência, onde mulheres, recém-nascidos e crianças têm direito a: 1) ampliação do acesso, acolhimento e melhoria da qualidade do pré-natal; 2) transporte para o prénatal e parto; 3 ) vinculação da gestante à unidade de referência para assistência ao parto "Gestante não peregrina!" e "Vaga sempre para gestantes e bebês!"; 4) realização de parto e nascimento seguros, por meio de boas práticas de atenção; 5) acompanhante no parto, de livre escolha da gestante; 6) atenção à saúde da criança de zero a 24 meses com qualidade e resolutividade; 7 ) acesso ao planejamento reprodutivo.

(g) Agradecemos a significativa colaboração das alunas do último ano do curso de Psicologia do Instituto de Educação Superior de Brasília: Claudia Carneiro, Cleuza Barbieri, Flavia Milea, Gabriela Macedo, Joziane Souza Moreira e Norma Susana Romero que, na prática "aprender fazendo", possibilitaram a empreitada de formar gestores e trabalhadores do SUS/DF no apoio institucional para mudanças de modelo de atenção e gestão. 
a análise, ao estranhar o cotidiano do trabalho, e cria condições para pactuação de decisões coletivas corresponsáveis. O apoio ativa a realização de encontros potentes para mudar essa realidade.

Outros desafios percebemos durante a implementação da PNH no DF:

a) rotatividade dos cargos, expressiva e desvinculada do desempenho positivo da gestão voltada para a efetivação do SUS. Durante o curso, regionais de saúde sofreram trocas sucessivas de diretores em efeito cascata, gerando desmotivação e baixa adesão às inovações trazidas pela $\mathrm{PNH}$;

b) baixa comunicação entre os médicos e outros profissionais; em geral, o profissional médico se exclui do trabalho em equipe e comporta-se como "dono" do cuidado, contribuindo para a clínica ser vista como uma abordagem medicocentrada sobre a doença; e, quando gestor das unidades, o médico não enfrenta seus pares que gerenciam sua própria agenda e o horário no serviço, sem cumprimento da jornada de trabalho;

c) faltam equipes multiprofissionais corresponsáveis pelo cuidado; em geral, profissionais de um setor não se articulam com os outros setores, não reconhecendo os limites do conhecimento e das tecnologias empregadas e, assim, deixam de garantir o seguimento da atenção;

d) falta entendimento de que a doença se manifesta, nos sujeitos, de forma singular;

e) insuficiência de vínculos entre profissionais e usuários, consequência de jornada de trabalho organizada em regime de plantão;

f) incômodo do trabalhador frente ao usuário, nas situações em que se vê convocado a mudar, para enfrentar desafios e aceitar sugestões de melhoria do processo de trabalho que o outro lhe traz. Exemplo disso foi a dificuldade de manutenção das reuniões com acompanhantes, espaço institucional democrático e potente para mudanças;

g) sobrecarga nos PS's, percebida pela equipe do ACR, que resulta na ausência de regulação interna e gestão do trabalho tanto no ambulatório quanto nas unidades de internação, além da frequente internação de pacientes, pelos médicos plantonistas, para cirurgias eletivas;

h) deficiência e inadequação da Ambiência nos serviços: falta de sinalização, iluminação deficiente, móveis sucateados, instalações sanitárias inadequadas, ambientes que comprometem a privacidade e individualidade do usuário.

Concluindo, para que o apoio institucional contribua nos processos de mudança na atenção e gestão, recomenda-se como fundamental: 1) Pactuações entre os entes federados envolvidos (federal, estadual e municipal) sobre o modo de gerir e de cuidar, segundo a $\mathrm{PNH}$; 2) Parceria entre o MS e o gestor responsável onde o apoio acontecerá, uma vez que o método da Política interfere na gestão, indissociável da atenção; 3) Inclusão de trabalhadores e usuários na gestão do cuidado, utilizando dispositivos da Política, com foco na desospitalização de pacientes que podem ser atendidos, de modo resolutivo, em outros pontos da rede e com a implementação de programas de atenção domiciliar; 4) Qualificação da Ambiência como espaço de encontro entre pessoas para produção de saúde, garantindo confortabilidade, privacidade e individualidade; 5) Referência do hospital para unidades de menor complexidade, segundo a lógica da integralidade em rede; 6) Garantia do apoio intensivo semanal nos processos de formação e intervenção conduzidos pela $\mathrm{PNH}$; 7) Composição dos coletivos regionais da $\mathrm{PNH}$ proporcionais aos processos de intervenção disparados pelo apoio institucional. 


\section{Colaboradores}

Maria Elizabeth Mori e Olga Vania Matoso de Oliveira participaram, igualmente, de todas as etapas de elaboração do artigo.

\section{Referências}

1. Amaral LS. Construindo Redes de Atenção à Saúde Primária: do Movimento Sanitarista ao PSF - uma revisão da literatura [trabalho de conclusão de curso]. Belo Horizonte: Universidade Federal de Minas Gerais; 2010.

2. Conselho Nacional de Secretários de Saúde. As Conferências Nacionais de Saúde: evolução e perspectivas. Brasília (DF): Conass; 2009. (Conass Documenta, 18).

3. Constituição Federal [Internet]. Artigo 196. 1988 [acesso 2013 Abr 27]. Disponível em: http://www.planalto.gov.br/ccivil_03/constituicao/constituicaocompilado.htm

4. Ministério da Saúde. Secretaria de Atenção à Saúde. Núcleo Técnico da Política Nacional de Humanização. HumanizaSUS: documento base para gestores e trabalhadores do SUS. 4a ed. Brasília (DF): MS; 2010.

5. Mori ME, Oliveira OVM. Os coletivos da Política Nacional de Humanização (PNH): a cogestão em ato. Interface (Botucatu). 2009; 13 Supl. 1:627-40.

6. Benevides R, Passos E. Humanização na Saúde: um novo modismo? Interface (Botucatu). 2005; 9(17):389-406.

7. Campos GWS. O anti-Taylor: sobre a invenção de um método para co-governar instituições de saúde produzindo liberdade e compromisso. Cad Saude Publica. 1998; 14(4):863-70.

8. Ministério da Saúde. Secretaria de Atenção à Saúde. Política Nacional de Humanização da Atenção e Gestão do SUS. Gestão participativa e cogestão. Brasília (DF): MS; 2009.

9. Campos GWS. Um método para análise e cogestão de coletivos: a constituição do sujeito, a produção de valor de uso e a democracia em instituições: o método da roda. São Paulo: Hucitec; 2000.

10. Ministério da Saúde. Diretrizes do apoio integrado para qualificação da gestão e da atenção no SUS: uma das estratégias utilizada pelo Ministério da Saúde no processo de cooperação a Estados e Municípios, como forma de potencializar a sua ação [Internet]. 2012 [acesso 2013 Abr 27]. Disponível em: http://portal.saude.gov.br/portal/ arquivos/pdf/diretrizes_100712.pdf

11. Ministério da Saúde. Secretaria de Atenção à Saúde. Núcleo Técnico da Política Nacional de Humanização. HumanizaSUS: visita aberta e direito a acompanhante. 2a ed. Brasília (DF): MS; 2007.

12. Ministério da Saúde. Secretaria de Atenção à Saúde. Política Nacional de Humanização da Atenção e Gestão do SUS. Acolhimento e classificação de risco nos serviços de urgência. Brasília (DF): MS; 2009.

13. Ministério da Saúde. Secretaria-Executiva. Núcleo Técnico da Política Nacional de Humanização. HumanizaSUS: ambiência. Brasília (DF): MS; 2004.

14. Ministério da Saúde. Secretaria de Atenção à Saúde. Política Nacional de Humanização da Atenção e Gestão do SUS. Trabalho e redes de saúde. Brasília (DF): MS; 2009. 
Mori ME, Oliveira OVM

Mori ME, Oliveira OVM. Apoyo institucional y cogestión: la experiencia de la Política Nacional de Humanización del Sistema de Salud Brasileño (SUS) en el Distrito Federal, Brasil. Interface (Botucatu). 2014; 18 Supl 1:1063-75.

El apoyo institucional de la Política Nacional de Humanización (PNH), del Ministerio de la Salud, Distrito Federal (DF), Brasil, de 2008 a 2013, comenzó en el Hospital de Base (HBDF) y se extendió hasta la Secretaría de Atención a la Salud (SAS). Fue dirigido a los cambios en los modelos de atención y gestión, y el fortalecimiento del SUS. En HBDF se llevaron a cabo las directrices (Cogestión, Hospitalidad, Ambiente) y dispositivos (Visita Abierta y Derecho a Acompañante, Colegiado Gestor, Consejo Gestor, Acogida y Clasificación de Riesgo y el Programa de Formación en Salud y Trabajo). En SAS, se ha implementado soporte para hacer frente a la superpoblación de la Urgencia y

Emergencia y para la creación del Colegiado Gestor. Insistimos en la importancia de la adhesión de los gestores para la aplicación de la PNH y consecución de los resultados deseados.

Palabras clave: Sistema de Salud Brasileño. Política Nacional de Humanización. Apoyo institucional. Cogestión. 
